Check for updates

1 Cicely Saunders Institute, King's College London, London, UK

2 Chesterfield Royal Hospital, Chesterfield, UK

3 Primary Care Unit, University of Cambridge, Cambridge, UK

Correspondence to: I J Higginson: irene.higginson@kcl.ac.uk Cite this as: BMJ 2021;373:n1437 http://dx.doi.org/10.1136/bmj.n1437 Published: 08 June 2021

\section{Dying at home during the pandemic}

\author{
Increase in home deaths could be because of preference or pressure \\ Irene J Higginson, ${ }^{1}$ David Brooks, ${ }^{2}$ Stephen Barclay ${ }^{3}$
}

Data from the Office for National Statistics show that covid-19 was responsible for most of the 76 ooo excess deaths during 2020 in England and Wales, with only around 2000 attributable to other causes. ${ }^{1}$ The number of deaths from all causes in private homes increased by about one third to 167000 in 2020, compared with an average of 125000 between 2015 and 2019.

Around 41 ooo more people died in private homes than in a normal year (which is more than half of the total number of excess deaths) but only a small number (just over 3000 or $7 \%$ ) were recorded as being due to covid-19. ${ }^{1}$ Most of these deaths at home were from underlying causes seen every year: dementias (which increased by 65\%), heart and lung diseases, cancers, and neurological diseases. ${ }^{2}$ Some covid-19 deaths that occurred at home may have been wrongly attributed to these conditions, especially early in the pandemic when symptoms were poorly understood and testing scarce. Nevertheless, this is still likely to represent a significant shift of people dying of causes other than covid-19 from hospital to home.

Many people prefer home over hospital for their end-of-life care, ${ }^{3}$ and, although some people do not have preferences regarding place of care,${ }^{4}$ the mismatch between preferences and reality is well documented. In one survey of 138 older adults in England, Ireland, and the US, 56\% of respondents said they would prefer to die at home, and one quarter specifically did not want to die in hospital. Despite this, most participants subsequently died in hospital. Only 25\% achieved their first preference. ${ }^{5}$

Preferences are influenced by trade-offs between competing priorities, expected outcomes, levels of engagement, and abilities to form and express preferences. ${ }^{6}$ Was the increase in home deaths during 2020 evidence of improved achievement of peoples' preferences or the result of pandemic related displacement from healthcare facilities?

Hospitals and community services worked hard to free up beds for increasing numbers of covid-19 admissions. This may have facilitated discharge of patients at the end of life, helping some to achieve their preference for home care. Alternatively, the pandemic may have influenced peoples' preferences outside hospitals-through concerns about restricted visiting, fear of infection, and motivation to reduce pressure on stretched hospital services.

Unfortunately, we have no systematic evidence about the quality of home care given to people towards the end of life during the pandemic. Such information is vital if we are to understand whether the increase in deaths in private homes is a reflection of preference or of poor quality alternatives because of pressured hospital services.

Care at home can be of high quality, ${ }^{7}$ particularly when home services are available at all times, symptoms are well controlled, and communication is timely and skilful. ${ }^{8}$ Rapid innovations to anticipatory prescribing by general practitioners observed during the pandemic may have aided symptom management for patients at home. ${ }^{9}$ However, the Marie Curie report on dying during the pandemic and other research present a mixed picture. ${ }^{1011}$ For people needing palliative care during the pandemic, research is urgently need to find out how well symptoms were controlled; how families, preferences, and priorities were supported; and how easily services were accessed, including by remote consultation.

\section{Sustaining the shift}

Any shift towards more deaths at home needs to consider the size of the community palliative care workforce. In 2018, researchers predicted that as the annual numbers of deaths increased over the coming two decades, community capacity would need to double unless hospital capacity increased substantially. ${ }^{12}$ During 2020, pressure on community palliative and end-of-life care surged, reaching levels of need not expected until 2040. Combined with existing gaps in the workforce, this suggests an urgent need to grow and train community clinicians skilled in palliative care.

Help from family members and informal carers is a critical and often overlooked component of care at home. The furlough scheme and increase in working from home may have made it easier for some people to provide the flexible care needed to support those important to them at the end of life. In research done before the pandemic, for example, support from family members significantly increased the odds (range 1.78 to 7.85 ) of patients with cancer dying at home. ${ }^{13}$ For others, however, pandemic restrictions such as shielding and travel bans may have prevented them from providing support.

A detailed plan for better palliative care, You matter because you are you, recently published by Cicely Saunders International, gives a comprehensive approach to filling the gaps in palliative and end-of-life care. ${ }^{14}$ Providing expertise in places where people are cared for, joining up care, empowering patients to access palliative care, and increasing community support, training, and research are all essential to ensure that patients receive high quality end-of-life care in the place of their choosing-often at home. ${ }^{14}$ 
Competing interests: We have read and understood BMJ policy on declaration of interests and declare the following interests: $\mathrm{IJH}$ received peer review grant funding to her university of employment from NIHR, UKRI, and charities, including Cicely Saunders International and Marie Curie, to study ways to improve palliative and end- of-life care, including at home. SB has received peer review grant funding to his university of employment from NIHR and charities including Marie Curie, to study ways to improve palliative and end-of-life care at home. The views expressed are those of the authors and not necessarily those of the NHS, the NIHR, or the Department of Health and Social Care.

Provenance and peer review: Commissioned; not externally peer reviewed.

1 Office for National Statistics. Deaths from all causes by place of death, England and Wales, deaths registered in 2020 and average for 2015 to 2019. 2021.https:/www.ons.gov.uk/peoplepopulationandcommunity/birthsdeathsandmarriages/deaths/articles/deathsathomeincreasedbyathirdin2020 whiledeathsinhospitalsfellexceptforcovid19/2021-05-07.

2 Office for National Statistics. Excess deaths in England and Wales, 2020: final. 2021. https://www.ons.gov.uk/peoplepopulationandcommunity/birthsdeathsandmarriages/deaths/datasets/excessdeathsinenglandandwales2020final.

3 Gomes B, Calanzani N, Gysels M, Hall S, Higginson IJ. Heterogeneity and changes in preferences for dying at home: a systematic review. BMC Palliat Care 2013;12:7. doi: 10.1186/1472-684X-12-7 pmid: 23414145

4 Hoare S, Morris ZS, Kelly MP, Kuhn I, Barclay S. Do patients want to die at home? a systematic review of the UK literature, focused on missing preferences for place of death. PLoS One 2015;10:e0142723. doi: 10.1371/journal.pone.0142723 pmid: 26555077

5 Higginson IJ, Daveson BA, Morrison RS, etalBuildCARE. Social and clinical determinants of preferences and their achievement at the end of life: prospective cohort study of older adults receiving palliative care in three countries. BMC Geriatr 2017;17:271. doi: 10.1186/s12877-017-0648-4 pmid: 29169346

6 Etkind SN, Bone AE, Lovell N, Higginson IJ, Murtagh FEM. Influences on care preferences of older people with advanced illness: a systematic review and thematic synthesis. J Am Geriatr Soc 2018;66:1031-9. doi: 10.1111/jgs.15272 pmid: 29512147

7 Gomes B, Calanzani N, Koffman J, Higginson IJ. Is dying in hospital better than home in incurable cancer and what factors influence this? A population-based study. BMC Med 2015;13:235. doi: 10.1186/s12916-015-0466-5 pmid: 26449231

8 Sarmento VP, Gysels M, Higginson IJ, Gomes B. Home palliative care works: but how? A meta-ethnography of the experiences of patients and family caregivers. BMJ Support Palliat Care 2017;7:0. doi: 10.1136/bmjspcare-2016-001141. pmid: 28232515

9 Antunes B, Bowers B, Winterburn I, etal. Anticipatory prescribing in community end-of-life care in the UK and Ireland during the COVID-19 pandemic: online survey. BMJ Support Palliat Care 2020;10:343-9. doi: 10.1136/bmjspcare-2020-002394 pmid: 32546559

10 Sleeman K, Murtagh F, Kumar R, et al. Better end of life 2021: dying, death and bereavement during covid-19. 2021. https://www.mariecurie.org.uk/globalassets/media/documents/policy/policy-publications/2021/better-end-of-life-research-report.pdf.

11 Oluyase AO, Hocaoglu M, Cripps RL, etalCovPall study team. The challenges of caring for people dying from covid-19: a multinational, observational study (CovPall). J Pain Symptom Manage 2021:S0885-3924(21)00159-7. doi: 10.1016/j.jpainsymman.2021.01.138. pmid: 33556496

12 Bone AE, Gomes B, Etkind SN, etal. What is the impact of population ageing on the future provision of end-of-life care? Population-based projections of place of death. Palliat Med 2018;32:329-36. doi: 10.1177/0269216317734435 pmid: 29017018

13 Gomes B, Higginson IJ. Factors influencing death at home in terminally ill patients with cancer: systematic review. BM/2006;332:515-21. doi: 10.1136/bmj.38740.614954.55 pmid: 16467346

14 Cicely Saunders International. You matter because you are you: an action plan for better palliative care. 2021. https://cicelysaundersinternational.org/action-plan-for-palliative-care/

This article is made freely available for use in accordance with BMJ's website terms and conditions for the duration of the covid-19 pandemic or until otherwise determined by BMJ. You may use, download and print the article for any lawful, non-commercial purpose (including text and data mining) provided that all copyright notices and trade marks are retained. 